\title{
Methods of Monitoring Training Load and Their Relationships to Changes in Fitness and Performance in Competitive Road Cyclists
}

Citation for published version (APA):

Sanders, D., Abt, G., Hesselink, M. K. C., Myers, T., \& Akubat, I. (2017). Methods of Monitoring Training Load and Their Relationships to Changes in Fitness and Performance in Competitive Road Cyclists. International Journal of Sports Physiology and Performance, 12(5), 668-675. https://doi.org/10.1123/ijspp.2016-0454

Document status and date:

Published: 01/05/2017

DOI:

10.1123/ijspp.2016-0454

Document Version:

Publisher's PDF, also known as Version of record

Document license:

Taverne

Please check the document version of this publication:

- A submitted manuscript is the version of the article upon submission and before peer-review. There can be important differences between the submitted version and the official published version of record.

People interested in the research are advised to contact the author for the final version of the publication, or visit the DOI to the publisher's website.

- The final author version and the galley proof are versions of the publication after peer review.

- The final published version features the final layout of the paper including the volume, issue and page numbers.

Link to publication

\footnotetext{
General rights rights.

- You may freely distribute the URL identifying the publication in the public portal. please follow below link for the End User Agreement:

www.umlib.nl/taverne-license

Take down policy

If you believe that this document breaches copyright please contact us at:

repository@maastrichtuniversity.nl

providing details and we will investigate your claim.
}

Copyright and moral rights for the publications made accessible in the public portal are retained by the authors and/or other copyright owners and it is a condition of accessing publications that users recognise and abide by the legal requirements associated with these

- Users may download and print one copy of any publication from the public portal for the purpose of private study or research.

- You may not further distribute the material or use it for any profit-making activity or commercial gain

If the publication is distributed under the terms of Article 25fa of the Dutch Copyright Act, indicated by the "Taverne" license above, 


\title{
Methods of Monitoring Training Load and Their Relationships to Changes in Fitness and Performance in Competitive Road Cyclists
}

\author{
Dajo Sanders, Grant Abt, Matthijs K.C. Hesselink, Tony Myers, and Ibrahim Akubat
}

\begin{abstract}
Purpose: To assess the dose-response relationships between different training-load methods and aerobic fitness and performance in competitive road cyclists. Method: Training data from 15 well-trained competitive cyclists were collected during a 10-wk (December-March) preseason training period. Before and after the training period, participants underwent a laboratory incremental exercise test with gas-exchange and lactate measures and a performance assessment using an 8-min time trial (8MT). Internal training load was calculated using Banister TRIMP, Edwards TRIMP, individualized TRIMP (iTRIMP), Lucia TRIMP (luTRIMP), and session rating of perceived exertion (sRPE). External load was measured using Training Stress Score (TSS). Results: Large to very large relationships $(r=.54-.81)$ between training load and changes in submaximal fitness variables (power at 2 and $4 \mathrm{mmol} / \mathrm{L}$ ) were observed for all training-load calculation methods. The strongest relationships with changes in aerobic fitness variables were observed for iTRIMP $(r=.81$ [95\% CI .51-.93, $r=.77$ [95\% CI .43-.92]) and TSS $(r=.75$ [95\% CI .31-.93], $r=.79$ [95\% CI .40-.94]). The strongest dose-response relationships with changes in the 8MT test were observed for iTRIMP ( $r=.63$ [95\% CI .17-.86]) and luTRIMP ( $r=.70$ [95\% CI .29-.89). Conclusions: Training-load quantification methods that integrate individual physiological characteristics have the strongest dose-response relationships, suggesting this to be an essential factor in the quantification of training load in cycling.
\end{abstract}

Keywords: heart rate, power output, endurance, cycling, training impulse

Competitive road cycling is a sport that involves a large volume of training and competition. ${ }^{1}$ As a consequence, cyclists experience high physiological and psychological demands during training and competition. It is important that the training program include a balance between training and rest to prevent both undertraining and overtraining and increase the chance of achieving the desired performance. ${ }^{2}$ As such, it is important for coaches to monitor cyclists' training load to determine whether a training variable requires adjustment. Fortunately, the proliferation of mobile power meters and heart-rate monitors, together with advanced traininganalysis software (eg, TrainingPeaks), has made monitoring such data accessible.

However, while access to data are now easier than ever, there is still considerable uncertainty around the validity of these data for quantifying load, particularly the dose-response validity. Although quantifying training load is an essential part of the training-monitoring process, ${ }^{3}$ the best methods for describing the dose-response validity in cycling are unknown. Banister proposed a training-load quantification method termed training impulse (TRIMP), which is an integration of training duration, mean heart rate (HR) of the training session and an exponential factor to weight the intensity of exercise. Since then the TRIMP method has been redefined, including 2 summated-zone TRIMP methods proposed by Edwards ${ }^{4}$ and Lucia et al, ${ }^{5}$ where the time spent in predefined HR zones is

Sanders, Myers, and Akubat are with the Sport, Exercise and Health Research Centre, Newman University, Birmingham, UK. Abt is with the Dept of Sport, Health and Exercise Science, University of Hull, Hull, UK. Hesselink is with the Dept of Human Movement Science, MUMC+, Maastricht, the Netherlands. Address author correspondence to Dajo Sanders at dajosanders@gmail.com. weighted using linear weighting factors. Manzi et $\mathrm{al}^{6}$ proposed the individualized TRIMP (iTRIMP) method, where the individual's HR-blood lactate relationship is used to calculate the exponential factor for weighting exercise intensity. In cycling, besides HR-based TRIMP methods, other methods of quantifying training load have been used based on session rating of perceived exertion (sRPE) ${ }^{7}$ or power output (Training Stress Score $\left.{ }^{\mathrm{TM}}[\mathrm{TSS}]\right){ }^{8}$ In order for a training-load measure to be valid and have practical application, the method used must be related to an outcome of importance. In most sports these are fitness, fatigue, or performance. Hence the chosen training-load measure should be selected on its ability to inform a dose-response relationship between the training load and the outcome of interest. ${ }^{6}$ To have an impact on performance, coaches must have an idea of the nature of the relationship between the prescribed exercise dose and the expected training outcome or response. This information allows them to be more proactive when manipulating the training dose instead of reacting to a response (eg, performance test). ${ }^{9}$ Studies evaluating this dose-response relationship are valuable since a better understanding of the dose-response relationship between training load, performance, fitness, and/or fatigue benefits applied practice.

The dose-response relationship can be evaluated by assessing changes in fitness and/or performance during a period of training monitoring. This has previously been shown in a study by Manzi et $\mathrm{al}^{6}$ with 8 recreational long-distance runners. Those authors reported that speed at $2 \mathrm{mmol} / \mathrm{L}$ and $4 \mathrm{mmol} / \mathrm{L}$ significantly increased after training and was very largely related to weekly iTRIMP $(r=.87$ [95\%CI .41-.97], .74 [95\%CI .07-.95]). Furthermore, there were very large inverse relationships between iTRIMP and both 5000-m $(r=-.77[95 \% \mathrm{CI}-.95$ to -.15$])$ and $10,000-\mathrm{m}(r=-.82[95 \% \mathrm{CI}$ -.96 to -.27$])$ running times. ${ }^{6}$ Weaker relationships were observed between Banister TRIMP (bTRIMP) and speed improvements at 2 $\mathrm{mmol} / \mathrm{L}$ and $4 \mathrm{mmol} / \mathrm{L}(r=.61$ [95\% CI -.91 to -.17$], .59$ [95\% CI 
-.91 to -.19$])$ and running performance $(r=-.41$ [95\% CI -.86 to $-.31],-.54$ [95\%CI -.90 to -.26$]$ ). Similar dose-response validity studies are lacking in cycling.

Even though internal-training-load methods such as bTRIMP, ${ }^{10}$ Lucia TRIMP (luTRIMP), ${ }^{5}$ and SRPE $^{11}$ and external training-load methods such as TSS ${ }^{12}$ are mentioned in the literature, there is little evidence of a dose-response relationship between these measures and training outcomes. Other measures of training load such as Edwards TRIMP (eTRIMP) and iTRIMP have been applied in other sports but not in cycling. Accordingly, this study examined the dose-response relationships between different training-load measures and changes in fitness and performance in well-trained competitive cyclists using a field-based approach.

\section{Methods}

\section{Participants}

Fifteen male competitive road cyclists (mean [SD] age 22 [2.5] $\mathrm{y}$, height 187.7 [4.2] cm, body mass 74.2 [4.7] $\mathrm{kg}$ ) volunteered to participate in the study. All were well-trained competitive cyclists, riding for Dutch club teams and Union Cycliste Internationale professional B teams, and active in national and international competitions. The participants had been active as competitive cyclists for at least 2 years, with a mean of 10 (4) years of competitive experience (including youth competitions). Written consent was obtained before participation, and institutional ethics approval was granted and in agreement with the Helsinki Declaration.

\section{Research Design}

Training data were collected during a 10-week preseason training period (December to February), where the training mainly consisted of low-intensity high-volume training. Before and after the training period, participants underwent a fitness and performance assessment. Riders were tracked and monitored throughout the training period using an online training diary (TrainingPeaks, Boulder, CO, USA). No training prescription was provided to the participants - they adhered to their own training plan or a plan provided by their coach.

\section{Fitness and Performance Assessment}

Before and after the training period, participants underwent a laboratory incremental cycling test with gas-exchange and blood lactate measures for the identification of individual HR-blood lactate relationships, lactate thresholds, and maximal oxygen uptake $\left(\dot{\mathrm{VO}}_{2 \max }\right)$. The incremental test started at $100 \mathrm{~W}$ and increased 40 W every 4 minutes until volitional exhaustion or when the pedaling cadence fell below $70 \mathrm{rpm}$ and the cyclist was not able to increase cadence. Each cyclist performed the test on his own bicycle, which was placed on an ergometer (Cyclus 2 ergometer, RBM Electronics, Leipzig, Germany). All tests were performed under similar environmental conditions $\left(17-18^{\circ} \mathrm{C}, 45-55 \%\right.$ relative humidity). HR was recorded every 5 seconds using a portable HR monitor (Cyclus2; RBM Electronics, Leipzig, Germany). The highest 30-second mean HR obtained during the incremental test was used as a measure of maximal $\mathrm{HR}\left(\mathrm{HR}_{\max }\right)$. Capillary blood samples were taken from a fingertip at the end of every 4-minute stage and directly analyzed using a portable lactate analyzer (Lactate Pro, Arkray KDK, Japan). As a measure of aerobic fitness, power outputs at $2 \mathrm{mmol} / \mathrm{L}$ and 4 $\mathrm{mmol} / \mathrm{L}$ blood lactate were calculated using publicly available soft- ware. ${ }^{13}$ The last completed stage was used as the measure of maximum aerobic power output $\left(\mathrm{W}_{\max }\right)$. If the stage was not completed, $\mathrm{W}_{\max }$ was calculated based on the fraction of the completed stage where volitional exhaustion occurred. ${ }^{14}$ Gas-exchange measures were obtained using an indirect calorimeter (Omnical, Maastricht Instruments, Maastricht, Netherlands) that was calibrated before testing according to the manufacturer's instructions. The test was performed until complete exhaustion to estimate $\mathrm{V}_{2}$ max. After the test, breath-by-breath values were visually inspected and $\dot{\mathrm{V}} \mathrm{O}_{2 \max }$ was defined as the highest 30 -second mean obtained during the test.

As an assessment of performance, the participants performed an 8-minute all-out time trial (8MT) in the field before and after the training period. The $8 \mathrm{MT}$ was performed directly after a controlled warm-up (10-20 $\mathrm{min}$ at $<60 \%$ power output at $4 \mathrm{mmol} / \mathrm{L}, 5 \mathrm{~min}$ at $90 \%$ power output at $4 \mathrm{mmol} / \mathrm{L}, 5 \mathrm{~min}$ at $<60 \%$ power output at 4 $\mathrm{mmol} / \mathrm{L}$ ), with the intensity for the warm-up based on the results of the pretraining laboratory test. Mean power output during the time trial was used as the performance measure.

\section{Training Load}

Training load was calculated using different methods based on either HR, power output, or RPE. bTRIMP was calculated based on training duration, HR, and a weighting factor using the following formula:

$$
\text { bTRIMP }=\text { duration training }(\min ) \times \Delta \mathrm{HR} \times 0.64 e^{1.92 \times}
$$

where $\Delta \mathrm{HR}=\left(\mathrm{HR}_{\mathrm{ex}}-\mathrm{HR}_{\mathrm{rest}}\right) /\left(\mathrm{HR}_{\mathrm{max}}-\mathrm{HR}_{\mathrm{rest}}\right), e=$ the base of the Napierian logarithms, 1.92 = a generic constant for males, and $x=\Delta \mathrm{HR}^{15}$ eTRIMP was calculated based on the time spent in 5 predefined HR zones multiplied by a zone-specific arbitrary weighting factor. $\mathrm{HR}$ zones were based on percentages of $\mathrm{HR}_{\max }$ (zone 1, 50-59\% $\mathrm{HR}_{\max }$ - weighting factor = 1; zone 2, 60-69\% $\mathrm{HR}_{\max }$ - weighting factor $=2$; zone $3,70-79 \% \mathrm{HR}_{\max }$ - weighting factor $=3$; zone $4,80-89 \% \mathrm{HR}_{\max }-$ weighting factor $=4$; zone 5 , $90-100 \% \mathrm{HR}_{\max }-$ weighting factor $=5$ ). Time spent in each zone is multiplied by the weighting factor and then summed to provide a total eTRIMP score. ${ }^{4}$ luTRIMP was calculated based on the time spent in 3 predefined HR zones. Zones were defined using fixed blood lactate concentrations with zone 1 below $\mathrm{LT}_{1}(2 \mathrm{mmol} / \mathrm{L})$, zone 2 between $\mathrm{LT}_{1}$ and $\mathrm{LT}_{2}(4 \mathrm{mmol} / \mathrm{L})$ and zone 3 above $\mathrm{LT}_{2}$, a different approach than the original luTRIMP, which used ventilatory thresholds to identify the zones. ${ }^{5}$ Zones were given coefficients of 1,2 , and 3 , respectively. Time spent in each zone is multiplied by the coefficient and then summed to provide a total luTRIMP score. ${ }^{5}$ iTRIMP was calculated by weighting exercise intensity according to an individual's own HR-blood lactate relationship and then using this to weight every HR rather than creating zones. An accumulated iTRIMP can then be calculated by summing the iTRIMP value for each HR data point. The individual weighting factor was calculated for each participant with the best-fitting method using exponential models as per the method of Manzi et al. ${ }^{6}$

As a subjective measure of internal training load, sRPE was calculated using the participant's RPE (CR-10 scale ${ }^{16}$ ) and session duration. The RPE was obtained 30 minutes after the training session based on the question "How hard was your workout?" Training load for the session was then quantified by multiplying the RPE by the duration of the session (min). ${ }^{7}$

As a measure of external training load, $\mathrm{TSS}^{8}$ was calculated using power output derived from portable power meters during every training session on the bike. TSS is calculated using the following formula: 


$$
\mathrm{TSS}=[(t \times \mathrm{NP} \times \mathrm{IF}) /(\mathrm{FTP} \times 3600)] \times 100
$$

where $t$ is the time, NP is normalized power, ${ }^{8}$ IF is an intensity factor, ${ }^{8}$ and FTP is the individual's functional threshold power. The 8MT was used to estimate participants' FTP, where $90 \%$ of the mean 8MT power output was used as an estimation of FTP. ${ }^{17,18}$ Power-output data were collected using different power-meter brands owned by the cyclists, which were calibrated according to the manufacturer's instructions before the training period: SRM system (SRM, Jülich, Welldorf, Germany), Power2max (Power2max, Chemnitz, Germany), PowerTap (CycleOps, Madison, WI, USA), SRAM Quarq (SRAM, Chicago, IL, USA), Rotor (Rotor bike components, Madrid, Spain), Stages power meter (Stages Cycling, Saddleback Ltd, UK), and Pioneer power meter (Pioneer, Kawasaki, Japan).

\section{Statistical Analysis}

Descriptive results are presented as mean (SD). Before analysis the assumption of normality was verified by using the ShapiroWilk W test. Differences in (aerobic) fitness variables between the pretesting and posttesting were assessed with paired-sample $t$ tests. Standardized effect size is reported as Cohen $d$, using the pooled $\mathrm{SD}$ as the denominator. Qualitative interpretation of $d$ was based on the guidelines provided by Hopkins ${ }^{19}: 0$ to 0.19 trivial, 0.20 to 0.59 small, 0.6 to 1.19 moderate, 1.20 to 1.99 large, $\geq 2.00$ very large. Inferences about the true effect are based on the width of the confidence interval relative to the smallest worthwhile change (SWC, $0.2 \times$ standardized effect). ${ }^{20}$ Dose-response relationships between measures of training load and aerobic fitness or performance were determined using Pearson product-moment correlation coefficients. Uncertainties in the correlation coefficients are presented as $95 \%$ confidence intervals. Interpretation of the strength of the correlation coefficients is based on guidelines provided by Hopkins ${ }^{19}: 0$ to .09 trivial, .1 to .29 small, .3 to .49 moderate, .50 to .69 large, .70 to .89 very large, .90 to .99 nearly perfect, 1.00 perfect.

\section{Results}

A total of 728 cycling training sessions were analyzed for the 15 participants during the 10 -week training period. Due to technological problems with some power meters, there are missing power output data for 3 participants. For those participants, training load was calculated using HR and sRPE data only. Mean weekly training load during the 10-week training period was measured at 1005 (229) arbitrary units (AU) for iTRIMP, 1090 (220) AU for bTRIMP, 891 (200) AU for luTRIMP, 2142 (432) AU for eTRIMP, 729 (193) AU for TSS, and 4086 (1460) AU for sRPE.

There was a moderate increase in $\dot{\mathrm{V}} \mathrm{O}_{2 \max }(+5 \%, P=.002, \mathrm{ES}=$ $0.73)$ and power output at $2 \mathrm{mmol} / \mathrm{L}(+7 \%, P<.001, \mathrm{ES}=0.72)$ after the training period. Small increases in power output at $4 \mathrm{mmol} / \mathrm{L}$ $(+4 \%, P<.001, \mathrm{ES}=0.56), \mathrm{W}_{\max }(+3 \%, P=.009, \mathrm{ES}=0.38)$, mean power output $(+1 \%, P=.490, \mathrm{ES}=0.25)$, and mean relative power output $(\mathrm{W} / \mathrm{kg})(+3 \%, P=.124, \mathrm{ES}=0.46)$ during the $8 \mathrm{MT}$ performance test were observed after the training period (Table 1).

Dose-response relationships between the different training-load measures and percentage changes in aerobic fitness and performance variables are presented in Table 2 . There were very large relationships observed between iTRIMP (Figure 1[A]) and TSS and

Table 1 Physiological and Performance Measures Before and After the 10-Week Training Period

\begin{tabular}{lccccc}
\hline & $\begin{array}{c}\text { Pretesting } \\
\text { mean (SD) }\end{array}$ & $\begin{array}{c}\text { Posttesting } \\
\text { mean (SD) }\end{array}$ & Mean difference [95\%Cl] & ES [95\% Cl] & Qualitative outcome \\
\hline$\dot{\mathrm{VO}}{ }_{2 \mathrm{max}}\left(\mathrm{mL} \cdot \mathrm{kg}^{-1} \cdot \mathrm{min}^{-1}\right)$ & $62(4)$ & $65(4)$ & $3.2^{* *}[1.4-4.9]$ & $0.73[0.31-1.14]$ & Very likely moderate effect \\
Power output at $2 \mathrm{mmol} / \mathrm{L}(\mathrm{W})$ & $282(28)$ & $303(32)$ & $22^{* *}[12-31]$ & $0.72[0.40-1.04]$ & Most likely moderate effect \\
Power output at $4 \mathrm{mmol} / \mathrm{L}(\mathrm{W})$ & $324(26)$ & $339(30)$ & $16^{* *}[9-22]$ & $0.56[0.31-0.91]$ & Most likely small effect \\
Maximal power output $(\mathrm{W})$ & $384(31)$ & $397(34)$ & $12^{* *[4-21]}$ & $0.38[0.11-0.65]$ & Likely small effect \\
8MT power output $(\mathrm{W})$ & $382(40)$ & $393(35)$ & $4[-8$ to 16$]$ & $0.25[-0.51$ to 1.01$]$ & Unclear small effect \\
8MT power output $(\mathrm{W} / \mathrm{kg})$ & $5.15(0.37)$ & $5.35(0.49)$ & $0.14[-0.43$ to 0.32$]$ & $0.46[-0.14$ to 1.06$]$ & Likely small effect \\
\hline
\end{tabular}

Abbreviations: CI, confidence interval; ES, effect size; $\dot{\mathrm{VO}}_{2 \max }$, maximal oxygen uptake; 8MT, 8-min time trial.

${ }^{a}$ With reference to a smallest worthwhile change of $0.2 \times$ standardized effect.

*Significant at the .05 level (2-tailed). **Significant at the .01 level (2-tailed).

Table 2 Relationship Between Training-Load Measures and Percentage Changes in Fitness Variables and Performance

\begin{tabular}{|c|c|c|c|c|c|c|}
\hline & SRPE & ITRIMP & bTRIMP & eTRIMP & IUTRIMP & TSS \\
\hline$\% \Delta \mathrm{PO} 2 \mathrm{mmol} / \mathrm{L}$ & $.54 *[.04-.82]$ & $.81 * *[.51-.93]$ & $.52 *[.01-.82]$ & $.64 *[.19-.87]$ & $.67 * *[.24-.88]$ & $.75^{* *}[.31-.93]$ \\
\hline$\% \Delta \mathrm{PO} 4 \mathrm{mmol} / \mathrm{L}$ & $.60 *[.13-.85]$ & $.77 * *[.43-.92]$ & $.67 * *[.24-.88]$ & $.73 * *[.35-.90]$ & $.72 * *[.33-.90]$ & $.79 * *[.40-.94]$ \\
\hline$\% \Delta \dot{\mathrm{V}} \mathrm{O}_{2 \max }$ & $.36[-.19$ to. 74$]$ & .08 [-.45 to. 57$]$ & $.37[-.18$ to. 74$]$ & .39 [-.15 to.75] & $.20[.35-.65]$ & .25 [-.38 to. 72$]$ \\
\hline$\% \Delta \mathrm{W}_{\max }$ & $.30[-.25$ to. 70$]$ & $.11[-.43$ to. 59$]$ & $.44[-.09$ to. 78$]$ & .43 [-.11 to.77] & .28 [-.27 to.69] & $.01[-.57$ to. .58$]$ \\
\hline$\% \Delta \mathrm{PO} 8 \mathrm{MT}$ & $.51[0-.81]$ & $.63 *[.17-.86]$ & $.40[-.14$ to. 76$]$ & .48 [-.04 to.80] & $.70 * *[.29-.89]$ & $.41[-.21-.80]$ \\
\hline$\% \Delta \mathrm{PO} / \mathrm{kg} 8 \mathrm{MT}$ & $.51[0-.81]$ & $.62 *[.16-.86]$ & $.63 *[.17-.86]$ & $.66^{*}[.22-.88]$ & $.76 * *[.41-.92]$ & $.61 *[.06-.88]$ \\
\hline
\end{tabular}

Note: Pearson product-moment correlation coefficients are presented with $95 \%$ confidence intervals.

Abbreviations: sRPE, session rating of perceived exertion; iTRIMP, individualized training impulse; bTRIMP, Banister training impulse; eTRIMP, Edwards training impulse; luTRIMP, Lucia training impulse; TSS, Training Stress Score; $\% \Delta$, percentage change pre vs post; PO power output; $\mathrm{VO}_{2 \max }$, maximal oxygen uptake; $8 \mathrm{MT}$, 8 -min time trial; $\mathrm{PO} / \mathrm{kg}$, relative power output (W/kg).

*Significant at the .05 level (2-tailed). **Significant at the .01 level (2-tailed). 

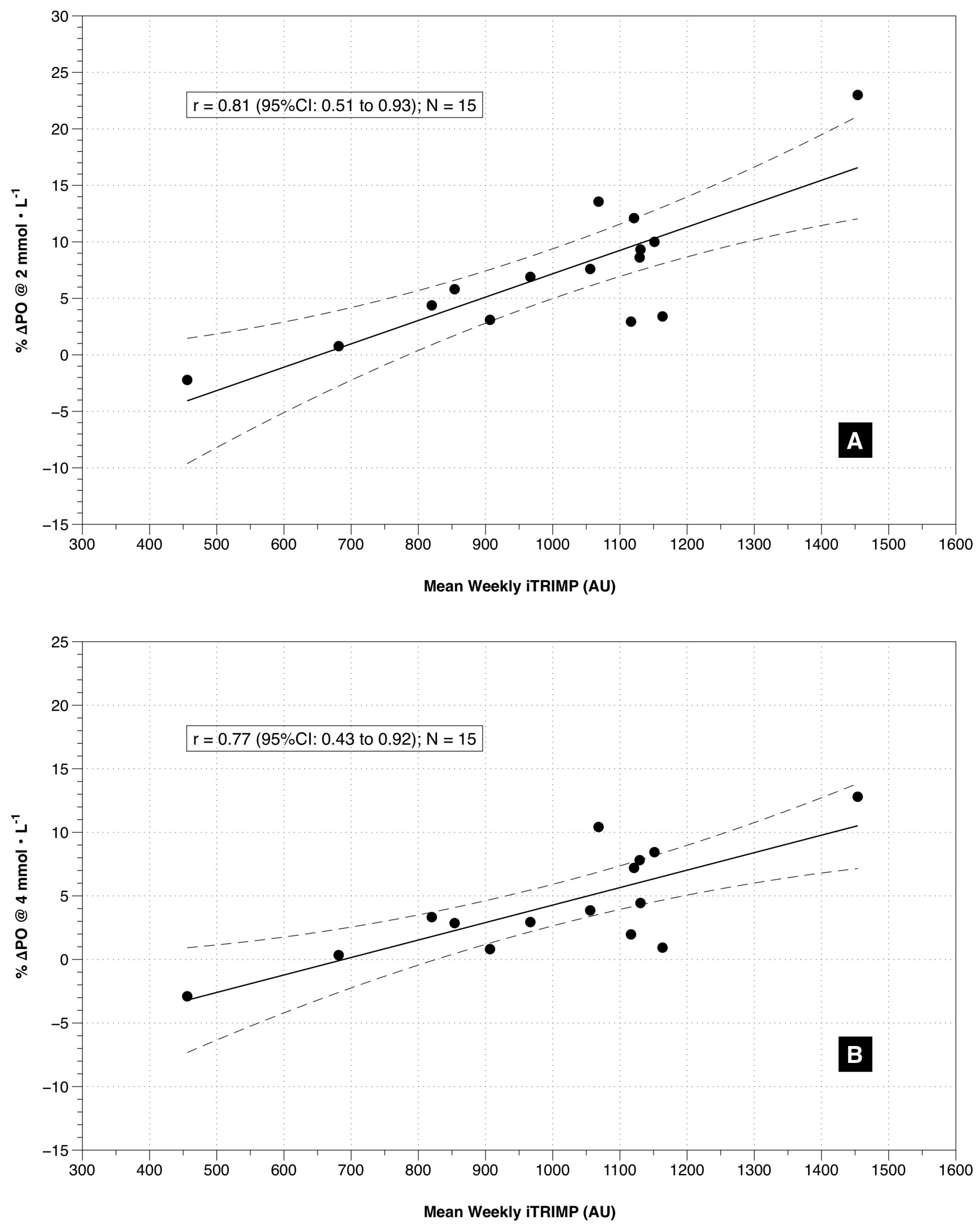

Figure 1 - Relationship between percentage changes in power output $(\Delta \mathrm{PO})$ at (A) 2 and (B) 4 mmol/L lactate and mean weekly individualized TRIMP (iTRIMP) $(\mathrm{N}=15)$. 
percentage changes in power output at $2 \mathrm{mmol} / \mathrm{L}$. Large relationships were observed for sRPE, bTRIMP, eTRIMP, and luTRIMP and changes in power output at $2 \mathrm{mmol} / \mathrm{L}$ (Figure 2). Percentage changes in power output at $4 \mathrm{mmol} / \mathrm{L}$ were very largely related to iTRIMP (Figure 1[B]), luTRIMP, eTRIMP, and TSS. Large relationships were observed for sRPE and bTRIMP. Large and very large relationships were observed for iTRIMP and luTRIMP and changes in power output during the 8MT performance test (Figure 3 ). When examining the dose-response relationship of improvement in relative power output $(\mathrm{W} / \mathrm{kg}$ ) during the $8 \mathrm{MT}$ and training load, there were very large relationships for luTRIMP and large relationships for eTRIMP, iTRIMP, bTRIMP and TSS, and sRPE.

\section{Discussion}

The aim of this study was to assess the dose-response relationships between different training-load measures and aerobic fitness and performance in well-trained competitive cyclists. Since the strongest dose-response relationships were observed with individualized training-load measures, the results of this study support the use of a training-load method that integrates individual physiological characteristics (ie, HR-blood lactate relationship, functional threshold power) rather than mean exercise-intensity values or arbitrary weighting factors.

We also observed considerable variation in the dose-response validity of the various methods examined. sRPE and bTRIMP showed the weakest relationships between training load and changes in power output at 2 and $4 \mathrm{mmol} / \mathrm{L}$ compared with the other measures of training load. The limitations of both methods could explain why they may be less suited for road cycling. bTRIMP uses mean HR of the training session or competition, which may not be applicable for the stochastic nature of (competitive) road cycling, where there are specific moments where the exercise intensity can be very high or very low depending on terrain, tactical factors, and weather conditions. ${ }^{1}$ Even though this stochastic nature may be less during training sessions, these fluctuations in exercise intensity limit the use of bTRIMP as a training-load measure in road cyclists. Furthermore, bTRIMP uses a generic equation for the blood lactate response to exercise, which does not integrate individual physiological characteristics. ${ }^{21}$ The complex interaction of many factors (eg, hormone concentrations, personality traits, environmental conditions $)^{3}$ that contribute to the RPE may explain the weaker dose-response relationships than with other training-load methods (eg, HR-based TRIMP methods). ${ }^{22}$ Nevertheless, the current study observed a stronger dose-response relationship for sRPE than found in previous research by Foster et $\mathrm{al}^{7}(r=.29)$ in a population of 56 athletes. Pinot and Grappe ${ }^{11}$ reported very large correlations ( $r=$ .83-.94) between increases in training load quantified by sRPE and mean maximal power outputs (5-240 min) achieved during training and competition each year. However, the study by Pinot and Grappe $^{11}$ was a case study conducted over an extended period of time, so it is hard to compare their results directly with ours. Wallace et $\mathrm{al}^{23}$ reported that correlations between total $\dot{\mathrm{V}}_{2}$ and training load were higher for bTRIMP $(r=.85)$ and luTRIMP $(r=.83)$ than sRPE $(r=.75)$, suggesting that HR-based methods relate better to total oxygen consumption than RPE-based methods. Therefore, even though sRPE is an easy-to-use and simple method, HR-based

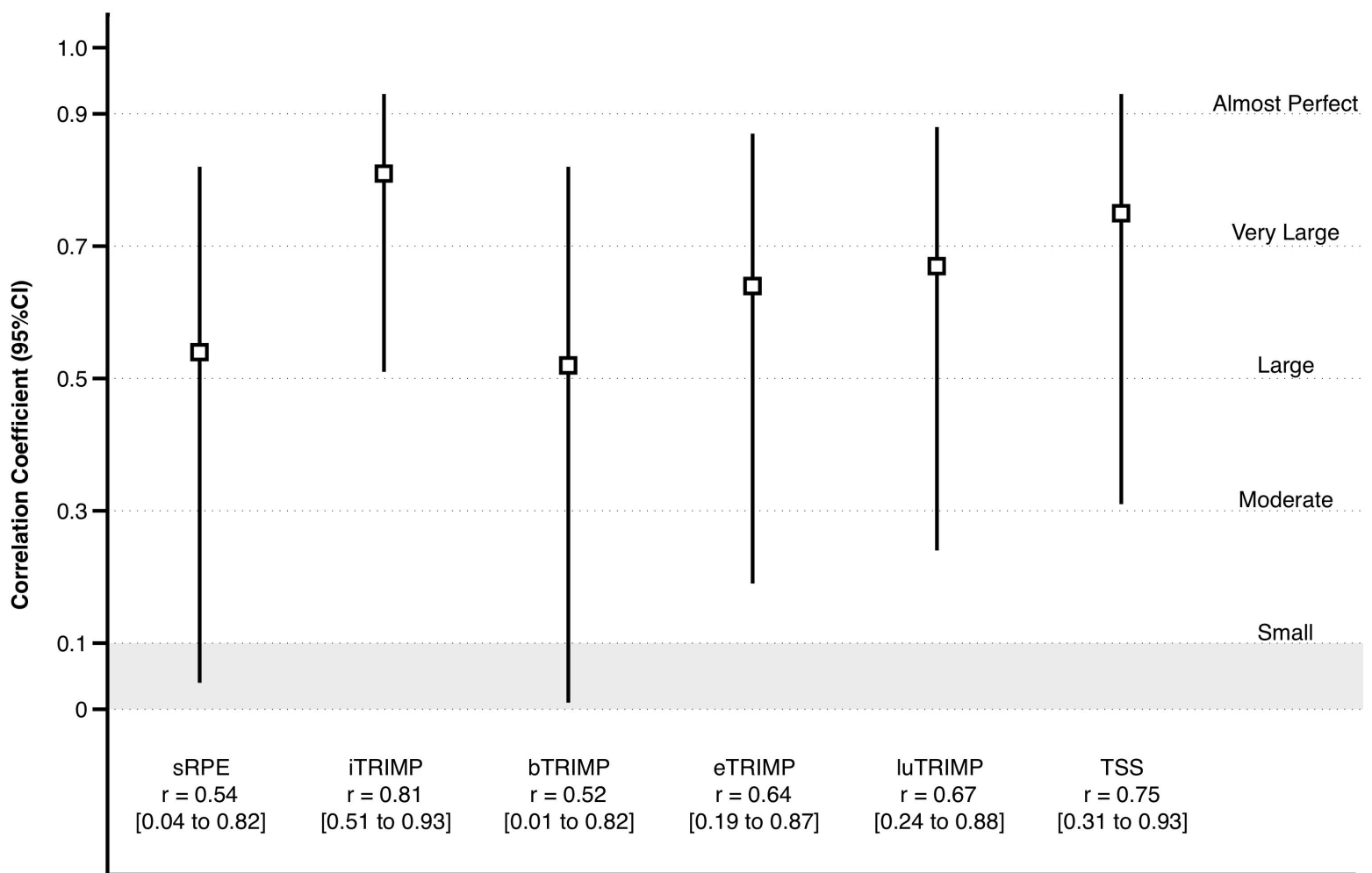

Figure 2 - Relationship between all the measures of training load and percentage changes in power output at 2 mmol/L lactate. Correlation coefficients $(r)$ are presented with $95 \%$ confidence intervals $(\mathrm{CI})$. Interpretation of the strength of the correlation coefficient was based on guidelines provided by Hopkins. ${ }^{19}$ Abbreviations: sRPE, session rating of perceived exertion; iTRIMP, individualized TRIMP. 


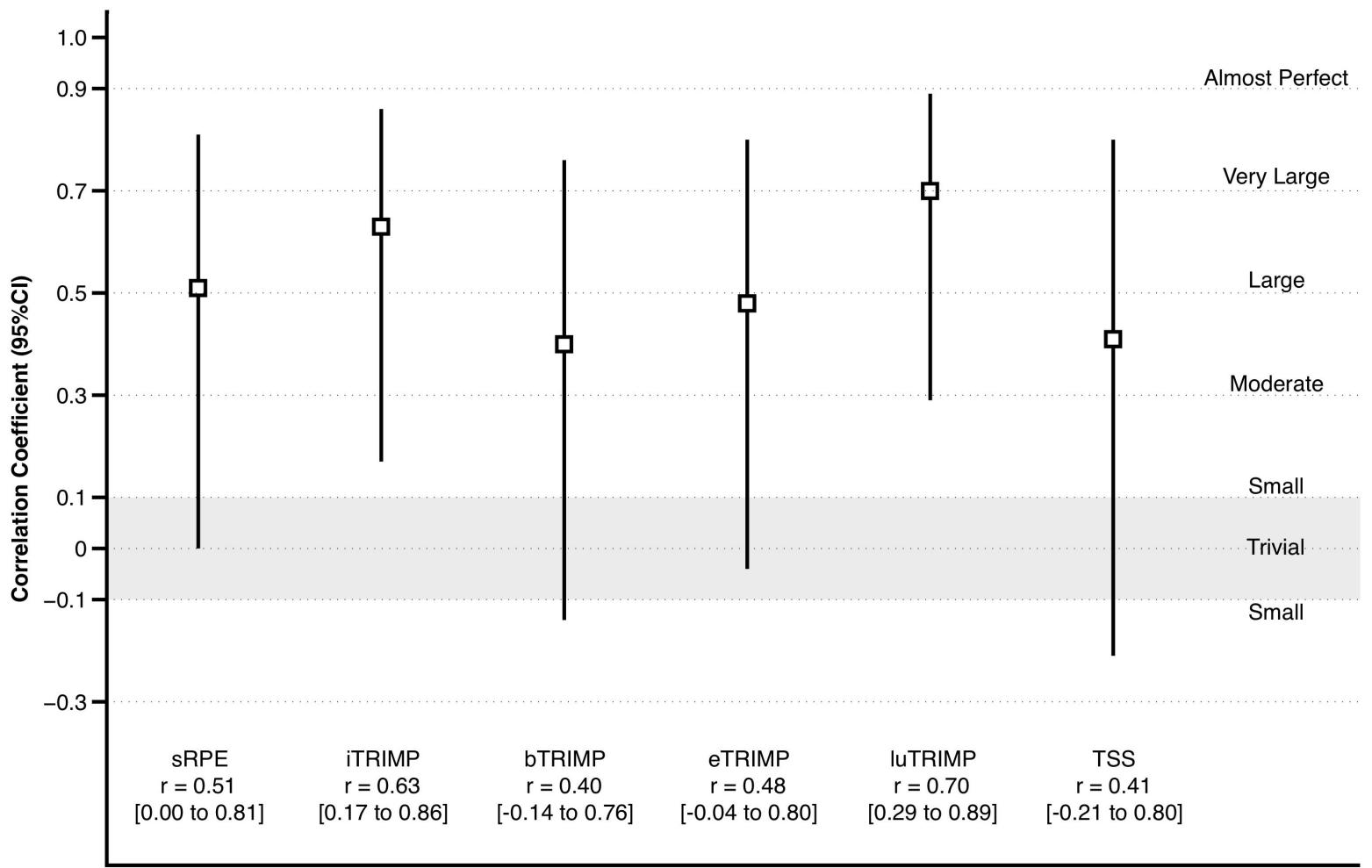

Figure 3 - Relationship between measures of training load and percentage changes in mean power output during an 8-minute performance test. Correlation coefficients $(r)$ are presented with $95 \%$ confidence intervals (CI). Interpretation of the strength of the correlation coefficient was based on guidelines provided by Hopkins. ${ }^{19}$ Abbreviations: sRPE, session rating of perceived exertion; iTRIMP, individualized TRIMP.

internal-training-load quantification appears to demonstrate higher dose-response validity when related to fitness or performance changes in cycling. ${ }^{22,23}$ However, in situations where the pattern of HR can be affected by accumulated fatigue, the combination of SRPE and HR-based training-load methods may be useful in providing information about cyclists' fatigue state. ${ }^{22,24}$ Since this study evaluated the dose-response validity in a preseason preparatory training period, future research should evaluate this in competitive periods where the nature of training differs (ie, more high-intensity training, increased training load) and the athletes are more prone to states of fatigue to see if these relationships are maintained.

There was a moderate relationship between TSS and the changes in mean power output during the 8MT performance test. Wallace et $\mathrm{al}^{25}$ reported higher correlations between a running-based version of TSS and changes in performance $(r=.70)$ than with bTRIMP $(r$ $=.60)$ and $\operatorname{sRPE}(r=.65)$. Overall, the dose-response relationships between training-load methods and changes in performance were not as strong as those between training load and aerobic fitness variables. The high variability $(\mathrm{ES}=0.25[95 \% \mathrm{CI}-0.51$ to 1.01$])$ observed in the improvement of the 8MT may provide explanations for these mixed results. Postrace fatigue and motivational factors could contribute to this variability in the results, as the posttraining 8MT tests were performed when the competitive season had started. Furthermore, the relatively short duration of the performance test may contribute to these results. Time trials of longer duration (20-90 $\mathrm{min}$ ) have been shown to have strong relationships with incremental-exercise-test variables. ${ }^{26-28}$ However, shorter tests are easier to integrate into the busy training plan of these athletes and are less physically and mentally demanding. Taking these factors into account, the dose-response relationships with performance in this study should be interpreted with caution.

As highlighted by the mixed results of the performance test, studies in the field with well-trained athletes make collecting training data less controlled than with laboratory-based research designs. However, using a field-based approach provides higher external validity and valuable information for coaches and practitioners working in the field, which may outweigh some of the limitations resulting from such an approach. In addition, different power meters were used in this study for the collection of HR and power data, leading to increased power-output data variability. Even though there is research validating some of the power-meter systems used in this study, ${ }^{29,30}$ not all power meters are tested for validity and accuracy. Furthermore, confounding factors regarding the interpretation and accuracy of blood lactate concentration measurement to track changes in training status must be taken into account. ${ }^{3}$ However, despite some of the limitations of blood lactate measurements, the dose-response relationships were shown using widely used methods of assessing endurance-performance variables in cycling.

\section{Practical Applications}

An improved understanding of the dose-response relationships between training load and fitness/performance is valuable for coaches and practitioners. To have an impact on performance we must be sure of the nature of the relationship between the prescribed exercise dose and the expected training outcome or response. Practically valuable information can be derived from the dose-response 
relationships presented. For example, the dose-response relationships between iTRIMP and aerobic fitness suggest that to maintain improvements in aerobic fitness (ie, power output at $2 \mathrm{mmol} / \mathrm{L}$ ) the cyclists should accumulate a mean weekly iTRIMP of $~ 650$ AU (Figure 1[A]). Furthermore, improvements in aerobic fitness will most likely occur when mean weekly iTRIMP $>650 \mathrm{AU}$ is implemented in the training plan. Even though this are only indicative data for this specific group of well-trained cyclists, providing coaches with such an evidence-based framework may contribute to optimized training monitoring and design of training programs. Future research should asses the relationships over more-prolonged training periods and possibly with more-frequent performance tests.

\section{Conclusions}

In conclusion, this study is the first to show the dose-response relationships between different training-load measures and changes in fitness and performance in well-trained cyclists. The strongest dose-response relationships between training load and changes in submaximal aerobic fitness variables were observed for iTRIMP and TSS, where $56 \%$ to $65 \%$ of the variance was explained. The dose-response relationships with performance changes were not as strong as the aerobic fitness variables, with the results showing iTRIMP and luTRIMP to have the strongest relationships. Overall, the results show that training-load quantification methods that integrate individual physiological characteristics have the strongest dose-response relationships, suggesting this to be an essential factor in the quantification of training load in cycling.

\section{References}

1. LuciaA, Hoyos J, Chicharro JL. Physiology of professional road cycling. Sports Med. 2001;31(5):325-337. PubMed doi:10.2165/00007256200131050-00004

2. Meeusen R, Duclos M, Foster C, et al. Prevention, diagnosis, and treatment of the overtraining syndrome: joint consensus statement of the European College of Sport Science and the American College of Sports Medicine. Med Sci Sports Exerc. 2013;45(1):186-205. PubMed doi:10.1249/MSS.0b013e318279a10a

3. Borresen J, Lambert MI. The quantification of training load, the training response and the effect on performance. Sports Med. 2009;39(9):779-795. PubMed doi:10.2165/11317780-00000000000000

4. Edwards S. The Heart Rate Monitor Book. New York: Polar Electro Oy; 1993.

5. Lucia A, Hoyos J, Santalla A, Earnest C, Chicharro JL. Tour de France versus Vuelta a España: which is harder? Med Sci Sports Exerc. 2003;35(5):872-878. PubMed doi:10.1249/01. MSS.0000064999.82036.B4

6. Manzi V, Iellamo F, Impellizzeri F, D’Ottavio S, Castagna C. Relation between individualized training impulses and performance in distance runners. Med Sci Sports Exerc. 2009;41(11):2090-2096. PubMed doi:10.1249/MSS.0b013e3181a6a959

7. Foster C, Daines E, Hector L, Snyder AC, Welsh R. Athletic performance in relation to training load. Wis Med J. 1996;95(6):370-374. PubMed

8. Coggan, AR. Training and racing using a power meter: an introduction. In: Level II Coaching Manual. Colorado Springs, CO: USA Cycling; 2003:123-145.
9. Akubat I, Van Winckel J. Training Load Monitoring in Soccer. In: Van Winckel J, Tenney D, Helsen W, Bradley P, Meert JP, McMillan K, eds. Fitness in Soccer: The Science and Practical Application. Klein-Gelmen, Belgium: Moveo Ergo Sum; 2014:167-184.

10. Padilla S, Mujika I, Orbananos J, Angulo F. Exercise intensity during competition time trials in professional road cycling. Med Sci Sports Exerc. 2000;32(4):850-856. PubMed doi:10.1097/00005768200004000-00019

11. Pinot J, Grappe F. A six-year monitoring case study of a top-10 cycling Grand Tour finisher. J Sports Sci. 2015;33(9):907-914. PubMed

12. Garvican LA, Pottgiesser T, Martin DT, Schumacher YO, Barras M, Gore CJ. The contribution of haemoglobin mass to increases in cycling performance induced by simulated LHTL. Eur J Appl Physiol. 2011;111(6):1089-1101. PubMed doi:10.1007/s00421-0101732-z

13. Newell J, Higgins D, Madden N, et al. Software for calculating blood lactate endurance markers. J Sports Sci. 2007;25(12):1403-1409. PubMed doi:10.1080/02640410601128922

14. Kuipers H, Verstappen FT, Keizer HA, Geurten P, van Kranenburg G. Variability of aerobic performance in the laboratory and its physiologic correlates. Int J Sports Med. 1985;6(4):197-201. PubMed doi:10.1055/s-2008-1025839

15. Banister EW. Modeling elite athletic performance. In: Macdouggal JD, Wenger HA, Green HJ, eds. Physiological Testing of Elite Athletes. Champaign, IL: Human Kinetics; 1991:403-422.

16. Borg G, Hassmen P, Lagerstrom M. Perceived exertion related to heart rate and blood lactate during arm and leg exercise. Eur J Appl Physiol Occup Physiol. 1987;56(6):679-685. PubMed doi:10.1007/ BF00424810

17. Klika RJ, Alderdice MS, Kvale JJ, Kearney JT. Efficacy of cycling training based on a power field test. J Strength Cond Res. 2007;21(1):265-269. PubMed doi:10.1519/00124278-20070200000047

18. Carmichael C, Rutberg J. The Time-Crunched Cyclist: Fit, Fast and Powerful in 6 Hours a Week. 2nd ed. Boulder, CO: Velo Press; 2012.

19. Hopkins WG. A scale of magnitudes for effect statistics. 2002. http:// sportsci.org/resource/stats/effectmag.html. Accessed September 1, 2015.

20. Hopkins WG, Marshall SW, Batterham AM, Hanin J. Progressive statistics for studies in sports medicine and exercise science. Med Sci Sports Exerc. 2009;41(1):3-13. PubMed doi:10.1249/ MSS.0b013e31818cb278

21. Banister EW. Modeling elite athletic performance. In: Macdougal JD, Wenger HA, Green HJ, eds. Physiological Testing of Elite Athletes. Champaign, Illinois: Human Kinetics; 1991:403-422.

22. Halson SL. Monitoring training load to understand fatigue in athletes. Sports Med. 2014;44(Suppl 2):S139-S147. PubMed doi:10.1007/ s40279-014-0253-z

23. Wallace LK, Slattery KM, Impellizzeri FM, Coutts AJ. Establishing the criterion validity and reliability of common methods for quantifying training load. J Strength Cond Res. 2014;28(8):2330-2337. PubMed doi:10.1519/JSC.0000000000000416

24. Rodríguez-Marroyo JA, Villa G, Garcia-Lopez J, Foster C. Comparison of heart rate and session rating of perceived exertion methods of defining exercise load in cyclists. J Strength Cond Res. 2012;26(8):2249_ 2257. PubMed doi:10.1519/JSC.0b013e31823a4233

25. Wallace LK, Slattery KM, Coutts AJ. A comparison of methods for quantifying training load: relationships between modelled and actual training responses. Eur J Appl Physiol. 2014;114(1):11-20. PubMed doi:10.1007/s00421-013-2745-1 
26. Bentley DJ, McNaughton LR, Thompson D, Vleck VE, Batterham AM. Peak power output, the lactate threshold, and time trial performance in cyclists. Med Sci Sports Exerc. 2001;33(12):2077-2081. PubMed doi:10.1097/00005768-200112000-00016

27. Bentley DJ, Newell J, Bishop D. Incremental exercise test design and analysis: implications for performance diagnostics in endurance athletes. Sports Med. 2007;37(7):575-586. PubMed doi:10.2165/00007256-200737070-00002

28. Hoogeveen AR. The effect of endurance training on the ventilatory response to exercise in elite cyclists. Eur J Appl Physiol. 2000;82(12):45-51. PubMed doi:10.1007/s004210050650
29. Gardner AS, Stephens S, Martin DT, Lawton E, Lee H, Jenkins D. Accuracy of SRM and power tap power monitoring systems for bicycling. Med Sci Sports Exerc. 2004;36(7):1252-1258. PubMed doi:10.1249/01.MSS.0000132380.21785.03

30. Bertucci W, Duc S, Villerius V, Pernin JN, Grappe F. Validity and reliability of the PowerTap mobile cycling powermeter when compared with the SRM Device. Int J Sports Med. 2005;26(10):868-873. PubMed doi:10.1055/s-2005-837463 